\title{
E2F1/TS Immunophenotype and Survival of Patients with Colorectal Cancer Treated with 5FU-Based Adjuvant Therapy
}

\author{
Violetta Sulzyc-Bielicka ${ }^{1} \cdot$ Pawel Domagala ${ }^{2}$. Dariusz Bielicki ${ }^{3} \cdot$ Krzysztof Safranow $^{4}$. \\ Wojciech Rogowski ${ }^{5}$. Wenancjusz Domagala ${ }^{2}$ (i)
}

Received: 16 July 2014 / Accepted: 15 January 2016 / Published online: 29 January 2016

(C) The Author(s) 2016. This article is published with open access at Springerlink.com

\begin{abstract}
The predictive value of thymidylate synthase (TS) expression alone for 5FU-based treatment of colorectal cancer (CRC) has not been clinically confirmed. Little is known on the association of expression of E2F1, which controls the transcription of genes encoding proteins engaged in DNA synthesis including $T S$, and survival of patients with CRC. The purpose of this study is to assess the correlation between expression of both E2F1 and TS in CRCs and survival of patients administered adjuvant 5FU-based chemotherapy, in order to find a better predictor of treatment outcome than expression of TS or E2F1 alone. Nuclear TS and E2F1 were detected by immunohistochemistry in tissue microarrays from 190 CRCs (Astler-Coller stage B2 or C). Multivariate analysis identified significant association of the combined E2F1+TS+ immunophenotype with worse $\mathrm{OS}(\mathrm{HR}=3,78, P=0,009)$ and DFS $(\mathrm{HR}=2,30, P=0,03)$ of patients with colon cancer. There were significant differences between E2F1+TS + and E2F1-TS- Kaplan-Meier survival curves in relation to DFS $(P=0.008)$ and $\mathrm{OS}(P=0.01)$. About 37 and $31 \%$ difference in 3-year DFS and OS respectively were seen between patients
\end{abstract}

Wenancjusz Domagala

wenek@pum.edu.pl

1 Department of Clinical Oncology, Pomeranian Medical University, Szczecin, Poland

2 Department of Pathology, Pomeranian Medical University, Unii Lubelskiej 1, 71-252 Szczecin, Poland

3 Department of Gastroenterology, Pomeranian Medical University, Szczecin, Poland

4 Department of Biochemistry and Medical Chemistry, Pomeranian Medical University, Szczecin, Poland

5 Department of Oncology, University of Warmia and Mazury, Olsztyn, Poland with E2F1+TS+ vs. E2F1-TS- colon cancer immunophenotype. The E2F1+TS+ immunophenotype may be a marker of poor prognosis (the worst DFS and OS) of patients with colon cancer treated with 5FU-based adjuvant therapy. A subgroup of patients with this immunophenotype may require different and perhaps more aggressive treatment than 5FU-based chemotherapy. Thus, the combined E2F1/TS immunophenotype could be a potential indicator of colon cancer sensitivity to $5 \mathrm{FU}$.

Keywords Colorectal cancer · E2F1 - Thymidylate synthase · 5FU-based therapy

\section{Introduction}

Adjuvant 5-fluorouracil (5FU)-based chemotherapy in stage III colorectal cancer (CRC) decreases the frequency of cancer relapse and reduces the risk of cancer associated deaths by $30 \%[1,2]$. In stage II colorectal cancer, the benefit of adjuvant chemotherapy is smaller, improving the 5-year survival rate by 3-6 \% [3]. In advanced CRC approximately $23 \%$ of patients will respond to $5 \mathrm{FU}$ treatment combined with leucovorin [4]. It follows that a sizable percentage of CRC patients will not benefit from adjuvant 5FU-based therapy but will experience toxic side effects of the therapy and unnecessary costs [5]. Therefore, it is essential to know precisely which patients will respond to this kind of therapy.

5 -fluorouracil has been used in cancer treatment for the past 40 years. $5 \mathrm{FU}$ is an uracil analog and a prodrug [6], which undergoes a biotransformation to pharmacologically-active metabolites. The main target of $5 \mathrm{FU}$ is thymidylate synthase (TS) because 5fluorodeoxyuridine-5'-monophosphate (FdUMP), a 5FU metabolite, binds TS and forms a stable ternary complex 
that prevents DNA synthesis [6]. Studies using CRC cell lines have suggested the predictive importance of TS expression with regard to 5FU-based chemotherapy [7]. However, clinical trials of predictive/prognostic significance of TS in CRC patients have reported discrepant findings [8-10]. Therefore it was concluded that TS expression alone could not be used in clinical practice as a predictive marker [11]. Recent findings clearly indicate that markers associated with the cell cycle can help to identify subgroups of CRCs sensitive to 5FU treatment [12-14]. The E2F1 transcription factor could be one of such markers because: (1) it regulates the expression of TS and other enzymes necessary for DNA synthesis, (2) deregulation of E2F1 is one of the initial events in colorectal carcinogenesis [15] and analysis of protein products of genes associated with carcinogenesis can help to clarify their biological role in CRC, (3) high TS expression in tumor cells may be induced by E2F1 overexpression [16, 17], (4) E2F1 may bind to the TS gene promoter region [17], (5) high correlation between TS gene and E2F1 gene expression was found [18], (6) most CRCs show varying degrees of E2F1 expression [19].

E2F1 belongs to a family of eight (E2F1-8) transcription factors which regulate the cell cycle [20]. The activation of E2F transcription factors through their release from phosphorylated pRB complexes leads to transcription of over 1200 genes [21] including TS and other genes involved in DNA synthesis [17, 22, 23]. E2F1 overexpression may promote proliferation or enhance apoptosis depending on the level of E2F1 deregulation and the cell context background [20].

Very few studies have addressed the issue of E2F1 expression and survival of patients with CRC treated with chemotherapy. These reports assessed small groups of patients at various stages of advanced colorectal cancer with discrepant results $[19,24]$. Hence, on one hand, the predictive value of assessment of TS expression alone for 5FU-based treatment of CRC has not been clinically confirmed. On the other hand, although E2F1 seems to be one of several potential predictors for response to 5FU-based therapy, because it controls the transcription of genes encoding proteins engaged in DNA synthesis including TS, little is known on the association of E2F1 protein expression and survival of patients with CRC.

Therefore, to find a better predictor of treatment outcome than TS or E2F1 alone, the aim of this study was to assess the correlation between immunohistochemically determined nuclear expression of both E2F1 and TS in CRCs and overall survival (OS) and disease free survival (DFS) of patients administered adjuvant 5FU-based chemotherapy.

\section{Materials and Methods}

\section{Patients}

The study group consisted of 190 consecutive patients (mean age $59.3 \pm 10.5$ ) who met the following criteria: (1) had undergone potentially curative colorectal resection for sporadic CRC (defined as an absence of relevant family history at the time of admission to the hospital). The surgical operations consisted of either a resection with lymphadenectomy or a total mesorectal excision for rectal carcinomas; (2) distant metastases were excluded on preoperative liver ultrasonography, chest X-ray, and during intraoperative exploration; (3) histopathologic diagnosis of invasive adenocarcinoma Astler-Coller stage B2 or C without involvement of resection margins was established; (4) had no chemotherapy prior to the operation; (5) received identical adjuvant 5FU-based therapy. All patients received the same adjuvant chemotherapy regimen ( 6 cycles of 5 day courses of $425 \mathrm{mg} / \mathrm{m}^{2}$ FU administered intravenously plus $20 \mathrm{mg} / \mathrm{m}^{2}$ leucovorin). The cycles were repeated every 4 weeks). A total of 40 patients with rectal tumors received postoperative radiotherapy (50,4 Gy). Of the 77 Astler-Coller stage B2 tumors, 36 were rectal cancers and, of these, $14(38.9 \%)$ patients received preoperative and $10(27.8 \%)$ received postoperative radiotherapy. Tissues from the former were obtained from post-therapeutic resection specimens. Since there were no statistically significant differences in TS and E2F1 expression between patients with rectal cancer who did or did not undergo preoperative radiotherapy [TS (51.6\% vs. $61.3 \%$ respectively, $P=0.38)$, E2F1 $(22.6 \%$ vs. $35.5 \%$ respectively, $P=0.24)$ ] the former were included in the study. Table 1 lists the clinico-pathological characteristics of the 190 tumors and patients. The Research Ethics Committee of the Pomeranian Medical University approved this study (KB-0080/101/09).

The time from surgery until the time of death due to cancer or to last known follow-up ( $\geq 36$ months from the operation) was regarded as OS, and the time until the first appearance of metastasis or local recurrence was regarded as DFS. The median follow-up was 51 months (mean 51.0 \pm 23.8 ; range 7-120). During the follow-up, 44 of the 190 (23.2\%) patients died of cancer. Recurrences were found in 73 patients. Four patients died for reasons unrelated to cancer and were treated as censored observations.

\section{Immunohistochemistry}

Tumor tissue was fixed in buffered $10 \%$ formalin and embedded in paraffin. Sections ( $4 \mu \mathrm{m}$ thick) were stained with hematoxylin and eosin for histopathological diagnosis. Tissue microarrays (TMs) were constructed as previously described [13, 14]. Slides with TMs were 
Table 1 Characteristics of the study group $(n=190)$

\begin{tabular}{cc} 
Age (years) & \\
$\leq 60$ & 100 \\
$>60$ & 90 \\
Sex & 86 \\
Females & 104 \\
Males & \\
Grade & 100 \\
G1+G2 & 90 \\
G3 & \\
Astler-Coller stage & 77 \\
B2 & 113 \\
C & \\
Site & 95 \\
Rectum & 95 \\
Colon & $(n=73)$ \\
Radiotherapy (rectal tumors) & 31 \\
Preoperative & 40 \\
Postoperative & 2 \\
Unknown & \\
\hline
\end{tabular}

${ }^{a}$ Including mucinous carcinoma

deparaffinized and rehydrated, and endogenous peroxidase activity was blocked. Slides were immersed in $\mathrm{pH}$ 9.0 buffer and heat induced antigen retrieval was performed in a pressure cooker (Pascal, DakoCytomation). Monoclonal TS-106 (Chemicon, Temecula, CA) antibody (dilution 1:50, incubation time $30 \mathrm{~min}$ ) and monoclonal E2F1 antibody (Santa Cruz Biotechnology, USA, dilution 1:100, incubation time $30 \mathrm{~min}$ ) were used, and the TMs were immunostained using the Dako Envision kit according to the manufacturer's instructions (Envision $\mathrm{TM}+$ peroxidase anti-mouse polymer labeled with horseradish peroxidase - Dako Co., Carpinteria, CA). The reaction was developed with a diaminobenzidine substrate - chromogen solution and slides were counterstained with hematoxylin. Appropriate positive and negative controls were run. The immunohistochemical procedure for all 190 tumors was run at the same time under identical conditions because tumor tissue cores were contained in only four slides. Immunohistochemistry for assessing the presence or absence of DNA mismatch repair (MMR) proteins was performed on 180 CRCs (10 tumors could not be assessed due to insufficient amount of tissue) as described in [14]. Immunohistochemistry with antibodies directed against MMR proteins has been regarded as an equivalent for microsatellite instability (MSI) testing [25]. Loss of MMR protein expression was defined as complete absence of nuclear staining in the presence of positive staining of stromal cells.

\section{Scoring}

Tumor cores were independently assessed by 2 observers (PD and WD) who were blinded to clinical and pathological data. In cases of disagreement, the result was reached by consensus. Semi-quantitative evaluation of immunostained sections was done using well defined and tested histo-score system [26]. Of three most frequently applied scoring systems used in the literature to determine the expression status of immunohistochemically assessed proteins. (i.e., intensity score, pattern score or both combined), we used intensity \& pattern score because it seems to be most reliable and proved to be useful and reproducible in assessment of immunohistochemical staining [26-28]. Both intensity $(0-3)$ and pattern (1-6) scores were assessed. Each intensity score was multiplied by its corresponding pattern score $(1=0-4 \%$ of positive tumor cells; $2=5-19$; $3=20-39 ; 4=40-59 ; 5=60-79 ; 6=80-100 \%)$ and these grades were added to give the final histo-score (a minimum value of zero and a maximum value of 18). In order to reach the histo-score all tumor cells in a core of the TM were counted. A histoscore value of 4 was adopted as a cut-off for stratification of E2F1expression into low ( $\leq 4, \mathrm{E} 2 \mathrm{~F} 1-)$ and high $(>4$, $\mathrm{E} 2 \mathrm{~F} 1+)$, because the histogram of E2F1 values showed a local minimum at this point that clearly divided the study population into two subgroups. Similarly as in [14], stratification of TS expression into low $(<2$, TS-) and high $(\geq 2, \mathrm{TS}+)$ was based on a local minimum in the histoscore histogram.

\section{Statistics}

Associations between the presence of high TS or E2F1 expression in tumors and other categorical variables were analyzed with the Fisher exact test. The KaplanMeier method was used for the univariate survival analysis, and the differences between groups were assessed by the log-rank test. A Cox proportional hazards model was used for univariate and multivariate analyses of factors associated with OS and DFS. The independent variables included in the model were: age, gender, tumor site (rectum vs. colon), Astler-Coller stage (C vs. B2), histological grade (G3+mucinous vs. $\mathrm{G} 1+\mathrm{G} 2)$, loss of MMR proteins, presence of high TS expression and presence of high E2F1 expression. A $p<0.05$ was considered statistically significant. STATISTICA version 10 (StatSoft Inc., Tulsa, USA) was used for the statistical analysis. 


\section{Results}

\section{E2F1 and TS Expression and Clinico-Pathologic Parameters}

TS expression (Fig. 1) and E2F1 expression (Fig. 2) were seen in nuclei of cancer cells. Mean and median histoscore values were 3.7 and 4.0, respectively for E2F1, and 4.0 and 3.0, respectively for TS. High TS (TS+) expression (histoscore $\mathrm{TS} \geq 2$ ) in tumor cell nuclei was noted in 128 out of 190 patients $(67.4 \%)$. High E2F1 $(\mathrm{E} 2 \mathrm{~F} 1+)$ expression (histoscore E2F1>4) was seen in $36.8 \%$ of patients ( 70 out of 190 patients). The E2F1+TS+ immunophenotype was found in 51 $(26.8 \%)$ patients, E2F1+TS- in $19(10.0 \%)$, E2F1TS+ in $77(40.5 \%)$ and E2F1-TS- in $43(22.6 \%)$ patients. Loss of MMR proteins was found in 31 out of $180(17.2 \%)$ CRCs.

We investigated associations of E2F1 and TS expression with the following parameters: age and gender of patients, tumor grade, stage, and tumor site. High TS expression in tumor cell nuclei was seen more often in tumors located in the colon compared with those in the rectum $(76.8 \%$ vs. $57.9 \%, P=0.008)$. High E2F1 expression was more frequent in tumors with $\mathrm{B} 2$ stage compared with $\mathrm{C}$ stage $(46.8 \%$ vs. $30.1 \%, P=0.02)$. It was also more frequent in females than in males although the difference did not reach statistical significance $(44.2 \%$ vs. $30.8 \%, P=0.07)$. There was no significant association between high E2F1 and high TS expression (high E2F1 expression was present in $30.7 \%$ of patients with low TS and in $39.8 \%$ of those with high TS, $P=0.26$ ). There was no significant correlation between MSI status and E2F1/TS positivity $(p=0.66)$.

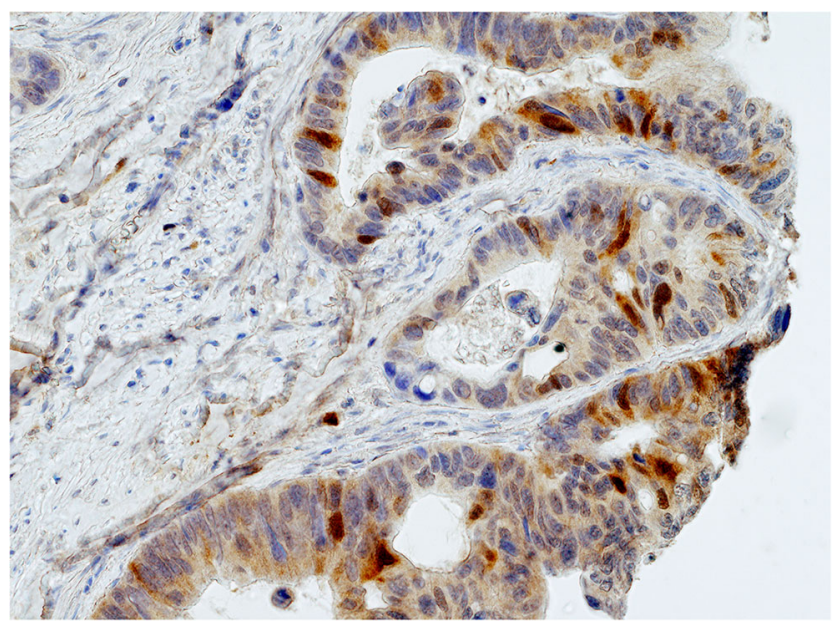

Fig. 1 Nuclear expression of TS (brown) in a colon carcinoma

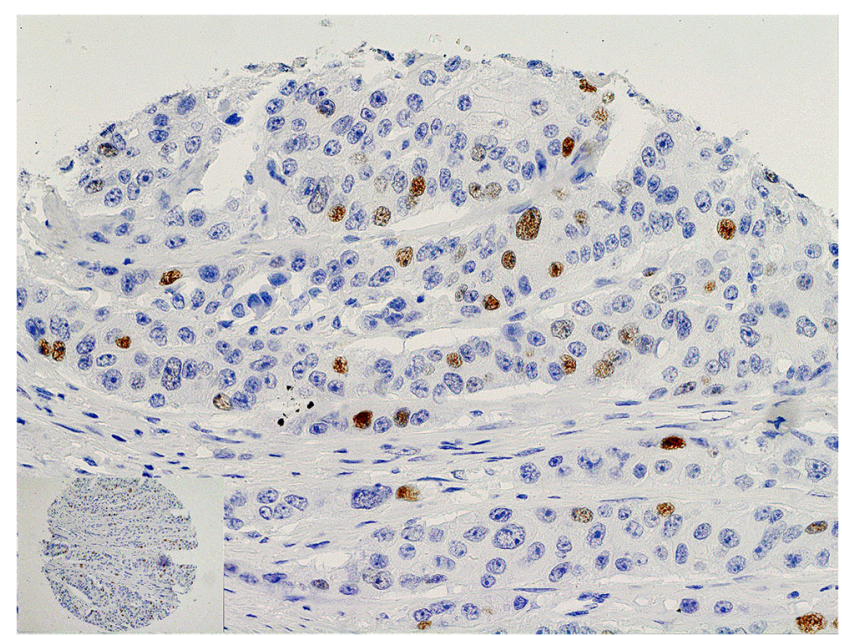

Fig. 2 Nuclear expression of E2F1 (brown) in a colon carcinoma. This is higher magnification of the upper portion of a core shown in an inset (lower left corner)

\section{Survival of Patients with CRC Defined by E2F1 and TS Expression}

Multivariate analysis involving sex, age, Astler-Coller stage, tumor grade, tumor site, loss of MMR proteins and separately E2F1 and TS expression in all patients $(n=180)$ identified significant associations only for Astler-Coller stage (C vs. B2) which was significantly associated with worse DFS $(\mathrm{HR}=3.01,95 \% \mathrm{CI}=1.66-5.46, P=0.0003)$ and $\mathrm{OS}$ $(\mathrm{HR}=3.24,95 \% \mathrm{CI}=1.49-7.03, P=0.003)$, male sex associated with worse $\mathrm{OS}(\mathrm{HR}=2.05,95 \% \mathrm{CI}=1.04-7.03$, $P=0.04$ ) and loss of MMR which was significantly associated with better DFS $(\mathrm{HR}=3.71,95 \% \mathrm{CI}=1.74-7.91$, $P=0.0007)$. The association of the loss of MMR proteins with OS did not reach statistical significance. However, multivariate analysis (Table 2) involving the above mentioned parameters and the combined E2F1+TS+ immunophenotype (high E2F1 and high TS expression) identified in addition to AstlerColler stage $(P=0.0001$ for DFS and $P=0.002$ for OS), sex ( $p=0.04$ for OS), grade ( $p=0.048$ for OS) and loss of MMR ( $p=0.02$ for DFS), significant association of E2F1+TS + immunophenotype with worse OS (HR $=2.35,95 \%$ $\mathrm{CI}=1.21-4.58, P=0.01)$ and DFS $(\mathrm{HR}=1.73,95 \%$ $\mathrm{CI}=1.01-2.98, P=0.047)$.

Because rectal cancers received pre- or postoperative radiotherapy and colon cancers did not, in order to see whether the results might depend on the site of the tumor, patients with tumors localized to the colon and rectum were analyzed separately.

\section{Colon}

Multivariate analysis involving sex, age, Astler-Coller stage, tumor grade, loss of MMR proteins and separately E2F1 and TS expression in patients with colon cancer 
Table 2 Colorectal cancer. Multivariate analysis of relations between expression of E2F1+ $\mathrm{TS}+{ }^{1}$, and other clinicopathological parameters, and OS and DFS $(n=180)$

\begin{tabular}{|c|c|c|c|c|}
\hline \multirow[t]{2}{*}{ Parameters } & \multicolumn{2}{|l|}{ DFS } & \multicolumn{2}{|l|}{ OS } \\
\hline & Hazard ratio $(95 \% \mathrm{CI})$ & $P$ & Hazard ratio $(95 \% \mathrm{CI})$ & $P$ \\
\hline Male Sex & $\begin{array}{l}1.60 \\
0.95-2.68\end{array}$ & 0.07 & $\begin{array}{l}2.03 \\
1.03-3.99\end{array}$ & 0.04 \\
\hline Age & $\begin{array}{l}1.01 \\
0.98-1.03\end{array}$ & 0.67 & $\begin{array}{l}1.01 \\
0.97-1.03\end{array}$ & 0.97 \\
\hline Astler-Coller C & $\begin{array}{l}3.13 \\
1.73-5.66\end{array}$ & 0.0001 & $\begin{array}{l}3.35 \\
1.55-7.22\end{array}$ & 0.002 \\
\hline Grade G3 & $\begin{array}{l}1.55 \\
0.94-2.53\end{array}$ & 0.09 & $\begin{array}{l}1.93 \\
1.01-3.68\end{array}$ & 0.048 \\
\hline Site rectum & $\begin{array}{l}1.05 \\
0.64-1.74\end{array}$ & 0.84 & $\begin{array}{l}1.03 \\
0.54-1.94\end{array}$ & 0.93 \\
\hline $\mathrm{E} 2 \mathrm{~F} 1+\mathrm{TS}+$ & $\begin{array}{l}1.73 \\
1.01-2.98\end{array}$ & 0.047 & $\begin{array}{l}2.35 \\
1.21-4.58\end{array}$ & 0.01 \\
\hline MSI & $\begin{array}{l}0.34 \\
0.13-0.85\end{array}$ & 0.02 & $\begin{array}{l}0.48 \\
0.17-1.38\end{array}$ & 0.17 \\
\hline
\end{tabular}

${ }^{1} E 2 F 1+$ high expression of E2F1, TS+ high expression of TS

$(n=90)$ identified only significant correlation of TS+ $(\mathrm{HR}=3.96,95 \% \mathrm{CI}=1.19-13.22, P=0.03)$, Astler Coller C stage $(\mathrm{HR}=3.01,95 \% \mathrm{CI}=1.29-7.02$, $P=0.01)$ and loss of MMR proteins ( $\mathrm{HR}=0.20,95 \%$ $\mathrm{CI}=0.04-0.86, P=0.03)$ with DFS. However, multivariate analysis involving the above mentioned parameters and the combined E2F1+TS+ immunophenotype identified significant association of E2F1+TS + immunophenotype with worse OS $(\mathrm{HR}=3.78,95 \% \mathrm{CI}=1.38-10.33, P=0.009)$ and with worse DFS $(\mathrm{HR}=2.30,95 \% \mathrm{CI}=1.08-4.90$, $P=0.03$ ) (Table 3). This association remained significant (OS $P=0.006$, DFS $P=0.02$ ) when only MSI negative cases were analyzed.

Kaplan-Meier survival curves confirmed the worst DFS (Fig. 3) and OS (Fig. 4) of patients with colon cancer exhibiting E2F1+TS+ immunophenotype. There were significant differences between E2F1+TS + and E2F1-TScurves in relation to DFS $(P=0.008)$ and OS $(P=0.01)$. For the combined E2F1/TS status, the 3-year DFS rates were $92 \%$ in 13 patients with both low E2F1 and low TS tumors, $55 \%$ in 31 patients with both high E2F1 and high TS tumors, $78 \%$ in 9 patients with high E2F1 and low TS tumors and $67 \%$ in 42 patients with low E2F1 and highTS tumors (Fig. 3). For the combined E2F1/TS status, the 3-year OS rates were $100 \%$ in 13 patients with both low E2F1 and low TS tumors, $69 \%$ in 31 patients with both high E2F1 and high TS tumors, $100 \%$ in 9 patients with high E2F1 and low TS tumors and $82 \%$ in 42 patients with low E2F1 and highTS tumors (Fig. 4). About 37 and $31 \%$ diference in 3-year DFS and OS respectively were seen between patients with E2F1+TS+ colon cancer immunophenotype as compared to E2F1-TSimmunophenotype (Figs. 3 and 4).
Table 3 Colon cancer. Multivariate analysis of relations between expression of E2F1+ $\mathrm{TS}+{ }^{1}$, and other clinicopathological parameters, and OS and DFS $(n=90)$

\begin{tabular}{|c|c|c|c|c|}
\hline \multirow[t]{2}{*}{ Parameters } & \multicolumn{2}{|l|}{ DFS } & \multicolumn{2}{|l|}{ OS } \\
\hline & Hazard ratio $(95 \% \mathrm{CI})$ & $P$ & Hazard ratio $(95 \% \mathrm{CI})$ & $P$ \\
\hline Male sex & $\begin{array}{l}1.54 \\
0.72-3.30\end{array}$ & 0.27 & $\begin{array}{l}2.29 \\
0.82-6.41\end{array}$ & 0.11 \\
\hline Age & $\begin{array}{l}1.10 \\
0.97-1.04\end{array}$ & 0.63 & $\begin{array}{l}1.00 \\
0.96-1.05\end{array}$ & 0.88 \\
\hline Astler-Coller C & $\begin{array}{l}2.77 \\
1.19-6.45\end{array}$ & 0.02 & $\begin{array}{l}2.59 \\
0.90-7.42\end{array}$ & 0.08 \\
\hline Grade G3 & $\begin{array}{l}1.65 \\
0.79-3.44\end{array}$ & 0.18 & $\begin{array}{l}1.18 \\
0.45-3.09\end{array}$ & 0.74 \\
\hline $\mathrm{E} 2 \mathrm{~F} 1+\mathrm{TS}+$ & $\begin{array}{l}2.30 \\
1.08-4.90\end{array}$ & 0.03 & $\begin{array}{l}3.78 \\
1.38-10.33\end{array}$ & 0.009 \\
\hline MSI & $\begin{array}{l}0.23 \\
0.05-0.98\end{array}$ & 0.047 & $\begin{array}{l}0.19 \\
0.02-1.44\end{array}$ & 0.11 \\
\hline
\end{tabular}

${ }^{1}$ E2F1+ high expression of E2F1, TS+ high expression of TS 


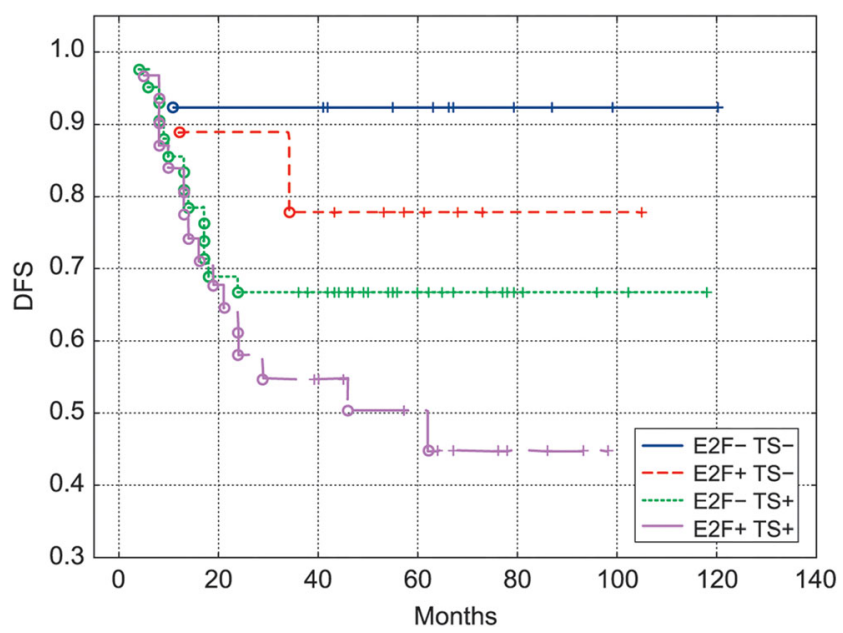

Fig. 3 DFS of patients with colon cancer $(n=95)$ treated with adjuvant chemotherapy, categorized according to the E2F1/TS expression. E2F1+ TS + curve differs significantly from E2F1-TS- curve $(P=0.008)$ but not from the other curves $(P=0.12 ; P=0.18$; for E2F1+TS-, E2F1-TS+ curves respectively)

\section{Rectum}

In patients with rectal cancer, $(n=90)$ there was no association between the E2F1/TS immunophenotype and DFS or OS ( $P=0.94$ and $P=0.76$ respectively for multivariate analysis).

There was significant interaction between the site of the tumor (colon vs. rectum) and the E2F1+TS+ immunophenotype with regard to an association with OS $(P=0.047)$ but significance of interaction was not achieved with regard to DFS $(P=0.15)$ in multivariate analysis. These findings indicate that only patients with colon cancer (but not those with rectal cancer) treated with adjuvant $5 \mathrm{FU}$ could be stratified into better or worse OS prognostic subgroups by TS and E2F1 expression.

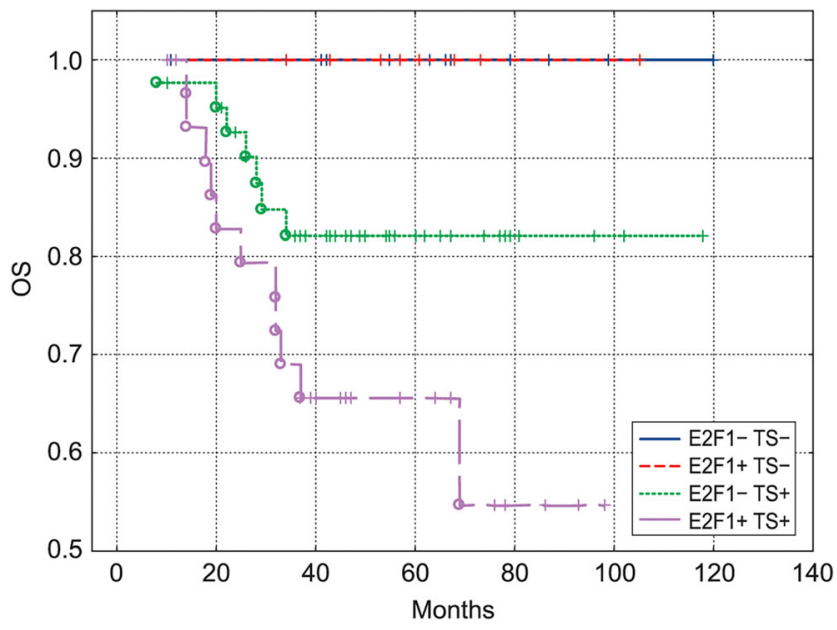

Fig. 4 OS of patients with colon cancer $(n=95)$ treated with adjuvant chemotherapy, categorized according to the E2F1/TS expression. E2F1+ TS + curve differs significantly from E2F1-TS- curve $(P=0.01)$ and from E2F1+TS- curve $(P=0.049)$ but not from E2F1-TS + curve $(P=0.07)$

\section{Discussion}

Despite numerous studies and clinical trials analysing predictive/prognostic significance of TS in CRC patients, TS expression alone has not been recommended in clinical practice as a predictive marker of 5FU-based treatment [11]. However, recent report clearly indicates that TS in combination with important regulators of the cell cycle ( $\mathrm{p} 53, \mathrm{p} 21^{\mathrm{WAF} 1}$ ) can better identify subgroups of CRCs sensitive to 5FU treatment than TS alone [14]. For reasons explained in the Introduction we hypothesized that the E2F1 transcription factor, as important cell cycle associated protein, together with TS could be a better predictor of treatment outcome than TS or E2F1 alone. It has been shown that E2F1-overexpressing cells had increased TS expression and experimental studies indicated that E2F1 induces various genes associated with $\mathrm{S}$ phase, including $T S[16,17]$.

In the present study we have compared E2F1/TS immunophenotype of CRCs with survival of patients treated with 5FU-based therapy. The results suggest that high E2F1 expression when combined with high TS expression predicts poor prognosis of patients with colon cancer treated with $5 \mathrm{FU}-$ based regimen. E2F1+TS+ immunophenotype was associated with poor DFS and OS whereas E2F1-TS- immunophenotype was associated with excellent survival. It seems that the worst survival of patients with colon cancer treated with 5FU-based regimen and exhibiting high TS expression may be attributed to TS expression induced by high level of E2F1 (E2F1+TS+ immunophenotype). Thus, our results are in line with studies which found that high $E 2 F 1$ expression in CRC cell lines was associated with low sensitivity to $5 \mathrm{FU}[29,30]$ and that high TS expression was associated with 5FU resistance [31]. Generally, irrespective of E2F1 expression, tumors exhibiting high TS expression in our study were refractory to treatment with 5FU-based therapy. However, some TS+ tumors were E2F1+ and others were E2F1- indicating different mechanisms used by tumor cells to increase TS level and acquire resistance to treatment.

E2F1's transcriptional regulation and responses of its downstream targets constitute a complex issue. E2F1 levels are dynamically and differentially regulated during the cell cycle because $E 2 F 1$ promoter is equipped with sites for both repression and activation [32]. Therefore, E2F1 may act as an oncogene or a tumor suppressor depending on tumor cell context i.e., E2F1 is mediating either cell proliferation and growth or tumor suppresion and apoptosis [20, 33, 34]. Although E2F1 induces apoptosis and decreased proliferation in cell lines [35, 36] and tumor tissue in CRCs [37], there is evidence that high E2F1 expression may be associated with CRC progression and metastasis [18, 38, 39]. Perhaps, in order to promote apoptosis or proliferation and survival of cells, different threshold levels of E2F1 are required for differential gene transactivation of its target gene promoters [20]. We speculate 
therefore that somewhat better survival of patients with tumors exhibiting E2F1+TS- immunophenotype, as compared to the worst survival associated with E2F1+TS+ immunophenotype, may reflect dual activity of $\mathrm{E} 2 \mathrm{~F} 1$ and point to the important role of increased TS expression which when induced by E2F1 may promote proliferation of tumor cells and resistance to 5FUbased treatment. E2F1 overexpressing human fibrosarcoma cells in culture had increased TS levels and were resistant to 5FU [16], which is consistent with colon cancers exhibiting E2F1+TS+ immunophenotype in our study. Interestingly, Banerjee et al. [16] have shown that cells overexpressing E2F1 were more sensitive to etoposide, doxorubicin, and SN38 , the active metabolite of irinotecan, despite being resistant to 5FU. It has to be shown whether colon cancers with E2F1+TS+ immunophenotype, may behave smilarly i.e., may be more sensitive to topo I inhibitors. There are only a few reports on the association between E2F1 expression alone and survival in CRC patients. These studies were based on small heterogeneous groups of patients and yielded conflicting results [19, 24].

TS is one of the basic enzymes participating in DNA synthesis, and serves as the molecular target for 5FU [6]. The results of studies on prognostic/predictive significance of TS expression alone in patients with CRC have been inconsistent and contradictory [11]. It has been suggested that resistance to 5FU chemotherapy cannot be assigned solely to TS or p53 expression [40] rather, markers associated with the cell cycle should be included in the search for predictive markers of benefit for 5FU-based chemotherapy in CRC [12]. As part of its important role in the cell cycle regulation, E2F1 activates the TS promoter and therefore it may influence the results of 5FU-based treatment of CRC $[17,22]$.

There is only one report in the literature in which expression of TS mRNA and E2F1 mRNA were compared in the same CRCs [18]. In that study increased $E 2 F 1$ and TS mRNA expression was noted in $14 \%$ of 23 CRCs. We found high expression of both E2F1 and TS protein in $27 \%$ of 190 CRCs but we noted intertumoral heterogeneity with respect to the combined E2F1/TS immunophenotype. An association of E2F1 expression with the level of TS was found in primary [18] and metastatic CRCs [39]. However, in another report based on 17 primary CRCs the level of E2F1 protein expression did not correlate with TS expression [24]. The results of our study suggest that this may be the result of intertumoral heterogeneity of E2F1/TS immunophenotype.

We did not find an association between E2F1/TS immunophenotype and OS or DFS of patients with rectal cancer. Although there were no statistically significant differences in TS and E2F1 expression between patients with rectal cancer who did or did not undergo preoperative radiotherapy, one cannot exclude the influence of preoperative radiotherapy on the expression of E2F1 and E2F1-dependent genes including $T S$. This aspect requires further study. We would like to mention also some limitations of this study. Although all patients received the same type of adjuvant chemotherapy, the series of patients in our study is relatively small and heterogenous. However, the associations we found were strong and highly significant.

We conclude that the E2F1+TS + immunophenotype may be a marker of poor prognosis (the worst DFS and OS) in patients with colon cancer treated with 5FU-based adjuvant therapy. It seems that subgroup of patients with this immunophenotype may require different and perhaps more aggressive treatment than 5FU-based chemotherapy. Thus, the combined E2F1/TS immunophenotype could be a potential indicator of colon cancer sensitivity to 5FU. Our results also suggest that one way to improve the results of treatment of TS+ colon cancer may be to look for drugs targeting E2F1 or downstream genes of E2F1 other than TS. However, our results are based on a retrospective study and require confirmation on larger number of colon cancer patients and in prospective randomized trials.

Acknowledgments This work was supported by the Pomeranian Medical University Research Program grant \#WL-125-01/S/11, \#WLBiML-401-01/3/12.

\section{Compliance with Ethical Standards}

Conflict of Interest The authors have declared no conflicts of interest

Open Access This article is distributed under the terms of the Creative Commons Attribution 4.0 International License (http:// creativecommons.org/licenses/by/4.0/), which permits unrestricted use, distribution, and reproduction in any medium, provided you give appropriate credit to the original author(s) and the source, provide a link to the Creative Commons license, and indicate if changes were made.

\section{References}

1. Wolpin BM, Meyerhardt JA, Mamon HJ, Mayer RJ (2007) Adjuvant treatment of colorectal cancer. CA Cancer J Clin 57: 168-185

2. Moertel CG, Fleming TR, Macdonald JS, Haller DG, Laurie JA, Goodman PJ, Ungerleider JS, Emerson WA, Tormey DC, Glick JH (1990) Levamisole and fluorouracil for adjuvant therapy of resected colon carcinoma. N Engl J Med 322:352-358

3. Quasar Collaborative Group, Gray R, Barnwell J, McConkey C, Hills RK, Williams NS, Kerr DJ (2007) Adjuvant chemotherapy versus observation in patients with colorectal cancer: a randomised study. Lancet 370:2020-2029

4. Advanced Colorectal Cancer Meta-Analysis Project (1992) Modulation of fluorouracil by leucovorin in patients with advanced colorectal cancer: evidence in terms of response rate. J Clin Oncol 10:896-903

5. Allegra C (2002) Thymidylate synthase levels: prognostic, predictive, or both? J Clin Oncol 20:1711-1713

6. Longley DB, Harkin DP, Johnston PG (2003) 5-Fluorouracil: mechanisms of action and clinical strategies. Nat Rev Cancer 3: $330-338$

7. De Angelis PM, Svendsrud DH, Kravik KL, Stokke T (2006) Cellular response to 5-fluorouracil (5-FU) in 5-FU-resistant colon cancer cell lines during treatment and recovery. Mol Cancer 5:20 
8. Edler D, Glimelius B, Hallstrom M, Jakobsen A, Johnston PG, Magnusson I, Ragnhammar P, Blomgren H (2002) Thymidylate synthase expression in colorectal cancer: a prognostic and predictive marker of benefit from adjuvant fluorouracil-based chemotherapy. J Clin Oncol 20:1721-1728

9. Soong R, Shah N, Salto-Tellez M, Tai BC, Soo RA, Han HC, Ng SS, Tan WL, Zeps N, Joseph D, Diasio RB, Iacopetta B (2008) Prognostic significance of thymidylate synthase, dihydropyrimidine dehydrogenase and thymidine phosphorylase protein expression in colorectal cancer patients treated with or without 5-fluorouracil-based chemotherapy. Ann Oncol 19:915-919

10. Popat S, Chen Z, Zhao D, Pan H, Hearle N, Chandler I, Shao Y, Aherne W, Houlston R (2006) A prospective, blinded analysis of thymidylate synthase and $\mathrm{p} 53$ expression as prognostic markers in the adjuvant treatment of colorectal cancer. Ann Oncol 17:18101817

11. Showalter SL, Showalter TN, Witkiewicz A, Havens R, Kennedy EP, Hucl T, Kern SE, Yeo CJ, Brody JR (2008) Evaluating the drugtarget relationship between thymidylate synthase expression and tumor response to 5 -fluorouracil. Is it time to move forward? Cancer Biol Ther 7:986-994

12. Bunz F (2008) Thymidylate synthase and 5-fluorouracil: a cautionary tale. Cancer Biol Ther 7:995-996

13. Sulzyc-Bielicka V, Domagala P, Urasinska E, Bielicki D, Safranow K, Domagala W (2011) Expression of p21WAF1 in Astler-Coller stage B2 colorectal cancer is associated with survival benefit from 5FU-based adjuvant chemotherapy. Virchows Arch 458:431-438

14. Sulzyc-Bielicka V, Domagala P, Bielicki D, Safranow K, Domagala W (2014) Thymidylate synthase expression and p21(WAF1)/p53 phenotype of colon cancers identify patients who may benefit from 5-fluorouracil based therapy. Cell Oncol 37:17-28

15. Enders GH (2004) Colon cancer metastasis: is E2F-1 a driving force? Cancer Biol Ther 3:400-401

16. Banerjee D, Schnieders B, Fu JZ, Adhikari D, Zhao SC, Bertino JR (1998) Role of E2F-1 in chemosensitivity. Cancer Res 58:42924296

17. DeGregori J, Kowalik T, Nevins JR (1995) Cellular targets for activation by the E2F1 transcription factor include DNA synthesis and G1/S-regulatory genes. Mol Cell Biol 15:4215-4224

18. Kasahara M, Takahashi Y, Nagata T, Asai S, Eguchi T, Ishii Y, Fujii M, Ishikawa K (2000) Thymidylate synthase expression correlates closely with E2F1 expression in colon cancer. Clin Cancer Res 6: 2707-2711

19. Bramis J, Zacharatos P, Papaconstantinou I, Kotsinas A, Sigala F, Korkolis DP, Nikiteas N, Pazaiti A, Kittas C, Bastounis E, Gorgoulis VG (2004) E2F-1 transcription factor immunoexpression is inversely associated with tumor growth in colon adenocarcinomas. Anticancer Res 24:3041-3047

20. Crosby ME, Almasan A (2004) Opposing roles of E2Fs in cell proliferation and death. Cancer Biol Ther 3:1208-1211

21. Muller H, Bracken AP, Vernell R, Moroni MC, Christians F, Grassilli E, Prosperini E, Vigo E, Oliner JD, Helin K (2001) E2Fs regulate the expression of genes involved in differentiation, development, proliferation, and apoptosis. Genes Dev 15:267-285

22. Dyson N (1998) The regulation of E2F by pRB-family proteins. Genes Dev 12:2245-2262

23. Yasui W, Fujimoto J, Suzuki T, Ono S, Naka K, Yokozaki H, Tahara E (1999) Expression of cell-cycle-regulating transcription factor E2F-1 in colorectal carcinomas. Pathobiology 67:174-179

24. Belvedere O, Puglisi F, Di Loreto C, Cataldi P, Guglielmi A, Aschele C, Sobrero A (2004) Lack of correlation between immunohistochemical expression of E2F-1, thymidylate synthase expression and clinical response to 5 -fluorouracil in advanced colorectal cancer. Ann Oncol 15:55-58

25. Shia J (2008) Immunohistochemistry versus microsatellite instability testing for screening colorectal cancer patients at risk for hereditary nonpolyposis colorectal cancer syndrome. Part I. The utility of immunohistochemistry. J Mol Diagn 10:293-300

26. Chung GG, Kielhorn EP, Rimm DL (2002) Subjective differences in outcome are seen as a function of the immunohistochemical method used on a colorectal cancer tissue microarray. Clin Colorectal Cancer 1:237-242

27. Detre S, Saclani Jotti G, Dowsett M (1995) A “quickscore" method for immunohistochemical semiquantitation: validation for oestrogen receptor in breast carcinomas. J Clin Pathol 48:876-878

28. Sulzyc-Bielicka V, Domagala P, Hybiak J, Majewicz-Broda A, Safranow K, Domagala W (2012) Colorectal cancers differ in respect of PARP-1 protein expression. Pol J Pathol 63:87-92

29. Obama K, Kanai M, Kawai Y, Fukushima M, Takabayashi A (2002) Role of retinoblastoma protein and E2F-1 transcription factor in the acquisition of 5-fluorouracil resistance by colon cancer cells. Int J Oncol 21:309-314

30. Yoshinare K, Kubota T, Watanabe M, Wada N, Nishibori H, Hasegawa H, Kitajima M, Takechi T, Fukushima M (2003) Gene expression in colorectal cancer and in vitro chemosensitivity to 5 fluorouracil: a study of 88 surgical specimens. Cancer Sci 94:633638

31. van Triest B, Pinedo HM, Blaauwgeers JL, van Diest PJ, Schoenmakers PS, Voorn DA, Smid K, Hoekman K, Hoitsma HF, Peters GJ (2000) Prognostic role of thymidylate synthase, thymidine phosphorylase/platelet-derived endothelial cell growth factor, and proliferation markers in colorectal cancer. Clin Cancer Res 6:1063-1072

32. Araki K, Nakajima Y, Eto K, Ikeda MA (2003) Distinct recruitment of E2F family members to specific E2F-binding sites mediates activation and repression of the E2F1 promoter. Oncogene 22:76327641

33. Yamasaki L, Jacks T, Bronson R, Goillot E, Harlow E, Dyson NJ (1996) Tumor induction and tissue atrophy in mice lacking E2F-1. Cell 85:537-548

34. Stanelle J, Stiewe T, Theseling CC, Peter M, Putzer BM (2002) Gene expression changes in response to E2F1 activation. Nucleic Acids Res 30:1859-1867

35. Elliott MJ, Dong YB, Yang H, McMasters KM (2001) E2F-1 upregulates c-Myc and p14(ARF) and induces apoptosis in colon cancer cells. Clin Cancer Res 7:3590-3597

36. Vorburger SA, Pataer A, Yoshida K, Liu Y, Lu X, Swisher SG, Hunt KK (2003) The mitochondrial apoptosis-inducing factor plays a role in E2F-1-induced apoptosis in human colon cancer cells. Ann Surg Oncol 10:314-322

37. Zacharatos P, Kotsinas A, Evangelou K, Karakaidos P, Vassiliou LV, Rezaei N, Kyroudi A, Kittas C, Patsouris E, Papavassiliou AG, Gorgoulis VG (2004) Distinct expression patterns of the transcription factor E2F-1 in relation to tumour growth parameters in common human carcinomas. J Pathol 203:744-753

38. Iwamoto M, Banerjee D, Menon LG, Jurkiewicz A, Rao PH, Kemeny NE, Fong Y, Jhanwar SC, Gorlick R, Bertino JR (2004) Overexpression of E2F-1 in lung and liver metastases of human colon cancer is associated with gene amplification. Cancer Biol Ther 3:395-399

39. Banerjee D, Gorlick R, Liefshitz A, Danenberg K, Danenberg PC, Danenberg PV, Klimstra D, Jhanwar S, Cordon-Cardo C, Fong Y, Kemeny N, Bertino JR (2000) Levels of E2F-1 expression are higher in lung metastasis of colon cancer as compared with hepatic metastasis and correlate with levels of thymidylate synthase. Cancer Res 60:2365-2367

40. Brody JR, Hucl T, Costantino CL, Eshleman JR, Gallmeier E, Zhu $\mathrm{H}$, van der Heijden MS, Winter JM, Wikiewicz AK, Yeo CJ, Kern SE (2009) Limits to thymidylate synthase and TP53 genes as predictive determinants for fluoropyrimidine sensitivity and further evidence for RNA-based toxicity as a major influence. Cancer Res 69:984-991 